cuidados de asepsia son los mismos que para enalquier intervención obstétrica.

En estas condiciones se introduce la mano, dehidamente lubricada, de lleno en la vagina, hasta llegar al cuello -del rual ya se tienen los datos referentes a dilatación. onsistencia, delgadez. etr.. detalles que se han obtenido con un tacto previ-. Ya la mano dentro de la vagina $Y$ al alcance del cuello. se insinúan entre éste y los cotiledones placentarios los dedos que permita pasar el cuello con comodidad I. se iniria el desprendimiento de la masa placentaria procediendo con cuidado $y$ orden. desprendiendo primero una mitad y luégo la otra, con suavidad $y$ asegurándose que no quede nin- gún cotiledón que pudiere provocar la persistencia de la hemorragia. Se aprecia que la placenta está totalmente desprendida cuando los dedos alcanzan en el reborde placentario a percibir las membranas, si éstas no se han roto durante la intervención, en cuyo caso los dedos quedan libres en la cavidad del huevo. Es natural que si las membranas se han roto en el reborde placentario, se puede, de hecho, hacer la extracción de la placenta. En caso contrario, sería suficiente abandonar el órgano, ya que la integridad de las membranas pudiera ser útil para ayudar a completar la dilatación del cuello.

\title{
INFORMACIONES MEDICAS
}

XT rongreso de la: Sociedades Obstétricas y Ginecolójicas de Lengua Franiesa.

Del 5 al 10 de mavo de 1952 , se efectuará en Algeria y Túnez, el decimoquinto Congreso de la Federación de Sociedados Obstétricas y Ginecológicas dt Lengua Francesit. bajo el auspicio del gobernador gen ral de Algeria, del Rey de Túnez y del Presidente General de Francia.

El temario será el siguiente:

a) El pronóstico de la mola hidatidiforme.

b) El diagnóstico del cáncer del cuello uterino.

c) La anoxia fetal. d) Las distocias en el Africa Francesa.

Además de las sesiones cientificas. habrá una regia serie de agasajos a los congresistas $y$ una interesante exicursión por Aumale, Bon Saada. Biskra, Palermo y Nápoles.

Quienes deseen participar en este Congreso, pueden suscribirse, dirigiéndose al doctor Bonafos. Secretario General. 133, Rue Michelet. Algeria.

Con motivo de las bodas de plata de majisterio del Profesor Laffont, se editará un libro que contendrá artículos originales de los más eminentes Profesores de ginecología $y$ obstetricia, de lengua francesa. Preside las actividades para el mejor éxito de tan sugerente homenaje el Profesor Brindeau. 